\title{
Modeling the Deformed State of the Roadway on Permafrost
}

\author{
Aleksey KRAEV ${ }^{1}$, Andrey KRAEV ${ }^{1}$, Zurab SHANKHOEV ${ }^{1}$, Victor ISAKOV ${ }^{1}$ \\ ${ }^{1}$ Tyumen Industrial University, Tyumen, Russian Federation
}

\section{ABSTRACT}

For economic efficiency, the authors offer to conduct an experimental study of the deformed state of the sub-grade model on permafrost soils in the laboratory environment in a closed system (without a water flow) applying a geometric scale value of $M$ 1:30 and time scale of M 1:900. The description of the research flume, which allows simulating not only the deformed state of the linear structure, but also the temperature regime, is given. During the study, the defects were photo-recorded and the deformations of the structure were measured. Distribution isolines of vertical movements while freezing-thawing were built in the software system "Python", a thermogram of temperature changes in the body of the roadbed and the base of the road is given. The main conclusions of the research are formulated.

Key words: road, permafrost ground, numerical simulation, mound, freeze-thaw, roadbed, temperature condition.

\section{INTRODUCTION}

On the basis of the central research laboratory "Construction on permafrost" of the Tyumen Industrial University (TIU), an experimental laboratory study of the model of the subgrade and the base of the road on permafrost soils was carried out. For laboratory research, an experimental tray with geometric dimensions of 1200x1000x300 $\mathrm{mm}$ was developed. A schematic of the test tray is shown in Figure 1.

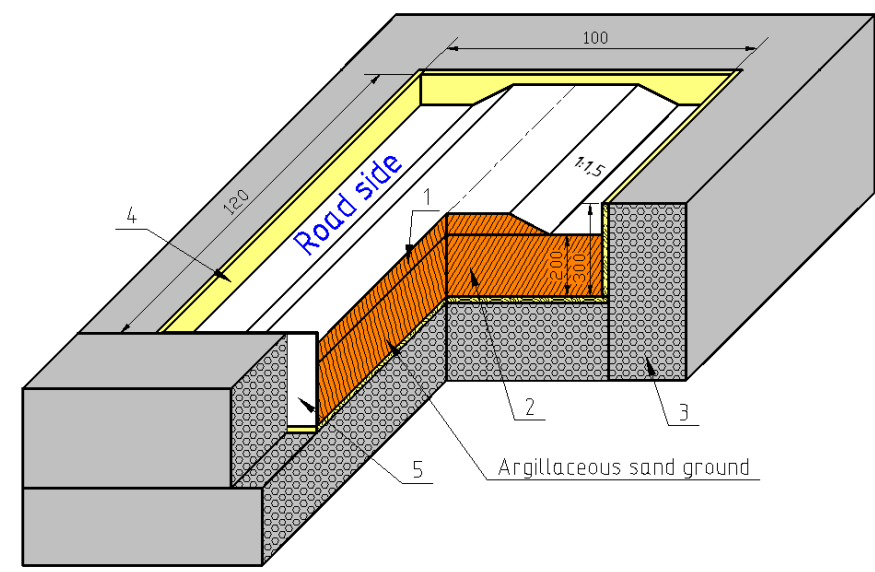

Figure 1: Scheme of a test tray for studying the deformed state of a model of a highway on permafrost soils

1- road bed of the motor road, 2 - base of the road bed of the motor road, 3 - insulation PPS-10, 4 - wooden frame of the test chute, 5 organic glass for photographic recording.

\section{SUBJECTS AND METHOD}

At the first stage of experimental studies, the model was tested in a closed system (without water inflow). A general view of the test tray is shown in Figure 2.

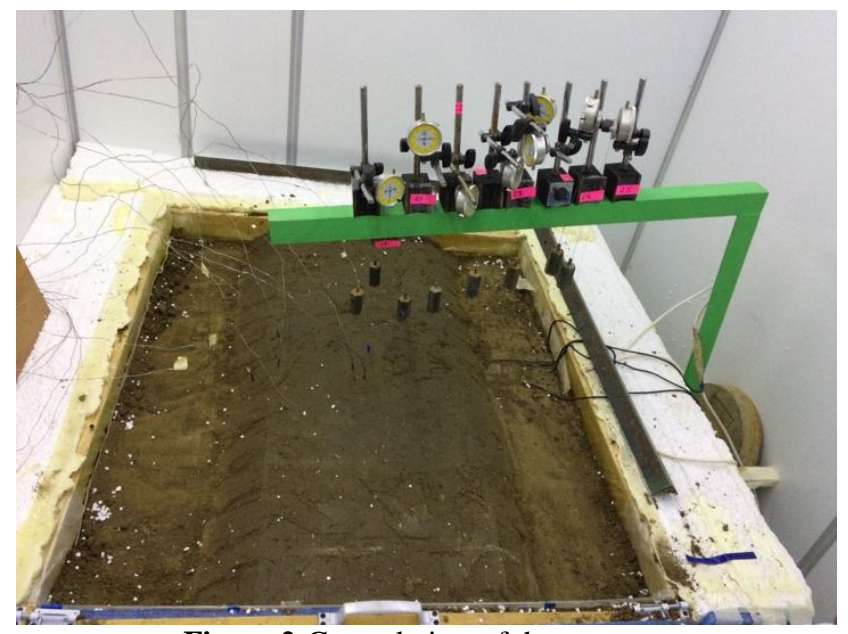

Figure 2:General view of the test tray.

When modeling the subgrade and the base of the highway on a scale of 1:30 [3], a homogeneous water-saturated loam with a disturbed structure was used.

In the freezer, the temperature and humidity stabilization of the base was preliminarily performed by cyclic freezing and thawing [3]. On a pre-stabilized foundation with a thickness of $\mathrm{h}=20 \mathrm{~cm}$, a subgrade was erected from cooled soil. The soil for the erection of the subgrade was kept in the freezer for 24 hours at a temperature of $\mathrm{T}=0^{\circ} \mathrm{C}$, which ensured the conditions for the erection of the subgrade close to natural ones. The road bed was modeled according to the first design principle.

The subgrade model was built with layer-by-layer compaction. The height of the simulated road embankment was $h=6.6 \mathrm{~cm}$. After the erection of the subgrade embankment, the slope part of the structure was profiled. The slope was taken equal to 1 : 1.5 .

To simulate difficult climatic conditions close to the object: "Construction of the highway Surgut - Salekhard, section of Novy Urengoy - Nadym. 1 start-up complex: Pangody village (km 870) - Pravokhetinsky village ( $k m$ 936). Adjustment "The test tray was placed in the freezer. Temperature conditions $T_{f, m}$ $=-14.8{ }^{\circ} \mathrm{C}$ and $\mathrm{T}_{\mathrm{th}, \mathrm{m}}=+10.0{ }^{\circ} \mathrm{C}$ were taken as average values based on long-term observations of positive and negative 
temperatures of a full-scale object [3]. The duration of the warm and cold periods was taken according to the method of V.D. Karlov [11]. When carrying out the experiment in laboratory conditions, the geometric scale of the object under study in the tray was 1:30, the time scale was 1: 900 , since the latter should be equal to the square of the scale of the linear dimensions. According to VSN 84-89, the calculated period of negative temperatures at a scale of 1: 1 is 5032.80 hours, the calculated period of positive temperatures at a scale of 1: 1 is 3727.20 hours. As a result, the value of the cold period for the experiment in laboratory conditions was $5.59 \mathrm{~h}$, the value of the warm period is $4.14 \mathrm{~h}$ [3]. The general view of the freezer is shown in Figure 3.

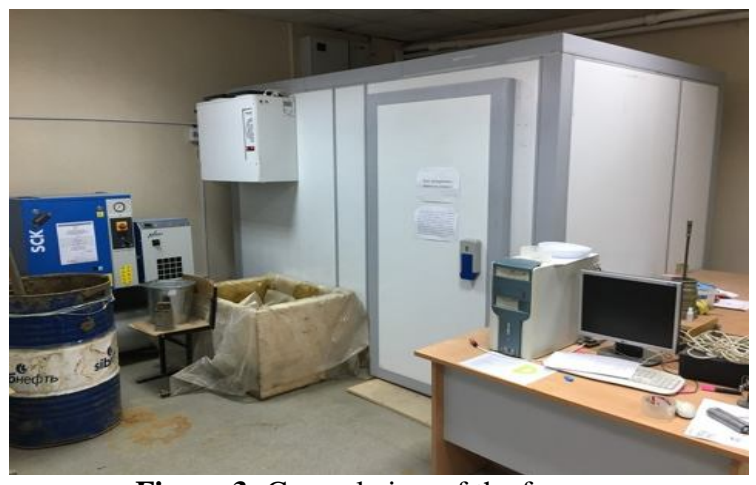

Figure 3: General view of the freezer.

The total number of freeze-thaw cycles of the roadbed and the base of the road was 15 , which corresponds to 15 years of the operational life of the linear facility. Qualitative and quantitative changes in the temperature regime and the deformed state of the object were observed in the first 10 cycles. In the next 5 cycles, cyclic repetitions of the deformed and temperature regime of the experimental model were observed $[12,13]$.

To measure the deformations of the body of the earthen floor and the base of the road, soil marks were used. Soil temperature was recorded using thermoelectric chromel-copel converters (thermocouple) of type L. Since the model under study is symmetric about the longitudinal axis of the structure, soil marks and thermocouples were distributed as follows: on the right side there were soil marks, on the left thermocouple. The arrangement of marks and thermocouples was performed symmetrically. The movements were fixed using a reference system, on which dial indicators were fixed with a measurement accuracy of $0.01 \mathrm{~mm}$. To fix the temperature, an IT-2-48 multichannel thermal conductivity meter was used. The layout of the soil marks and thermocouples is shown in Figure 4.

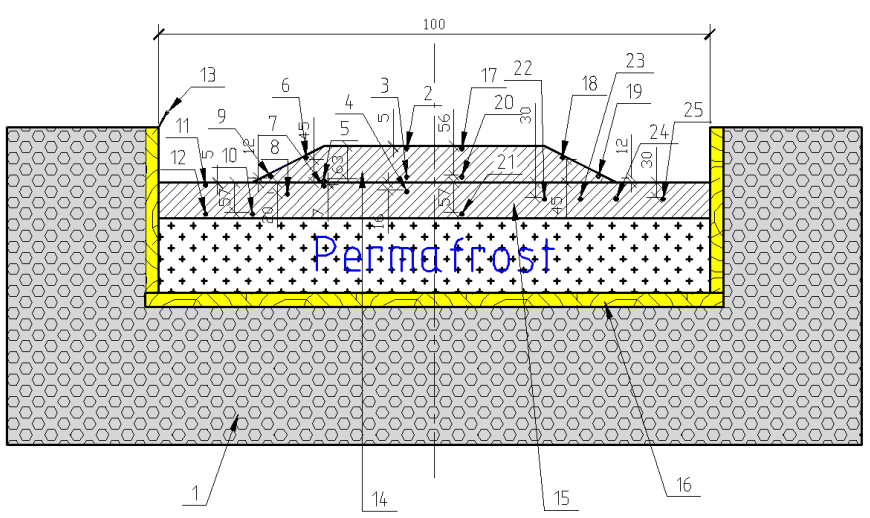

Figure 4: Arrangement of soil marks and thermocouples: 1 - insulation PPS-10; 2-13 - thermocouple numbers; 14 - roadbed of a motor road; 15 - the base of the road; 16 - wooden frame; 17-25 - soil marks.

During the experiment, photographs were taken of the state of the object. Figure 5 shows photographs of defects. During the third freezing cycle, cracks in the longitudinal and transverse directions were revealed in the body of the embankment. Cracks developed up to the eighth cycle with a maximum opening $\Delta=1 \mathrm{~mm}$, length $\mathrm{L}=60 \mathrm{~mm}$.

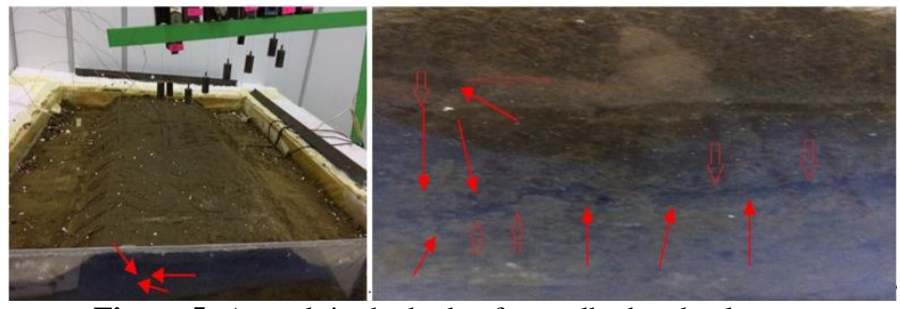

Figure 5: A crack in the body of a roadbed embankment.

Figure 6 shows the separation of the slope part of the roadbed from the base of the road. This defect was recorded during the fourth freeze-thaw cycle. The probable cause of the development of deformations is the rise of the simulated boundary of permafrost soils under the subgrade. The delamination of the slope part of the roadbed developed up to cycle 8 (Figure 6 ), with a maximum opening $\Delta=3 \mathrm{~mm}$, length $\mathrm{L}=1200 \mathrm{~mm}$.

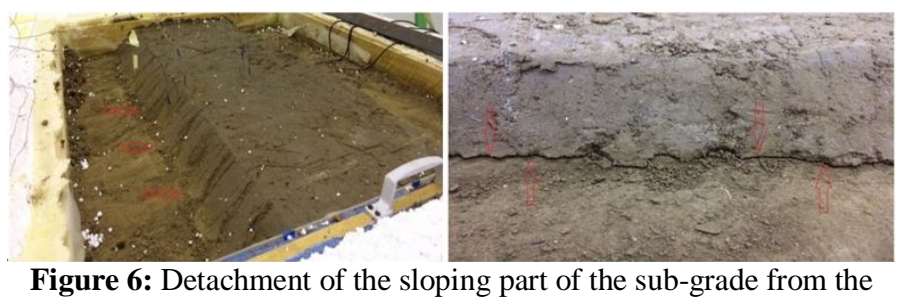
road base.

During the sixth cycle of the experiment, a crack (Figure 7) located transverse to the axis was recorded in the slope of the model of the roadbed. The maximum crack opening is $\Delta=1$ $\mathrm{mm}$, the length is $\mathrm{L}=100 \mathrm{~mm}$. 


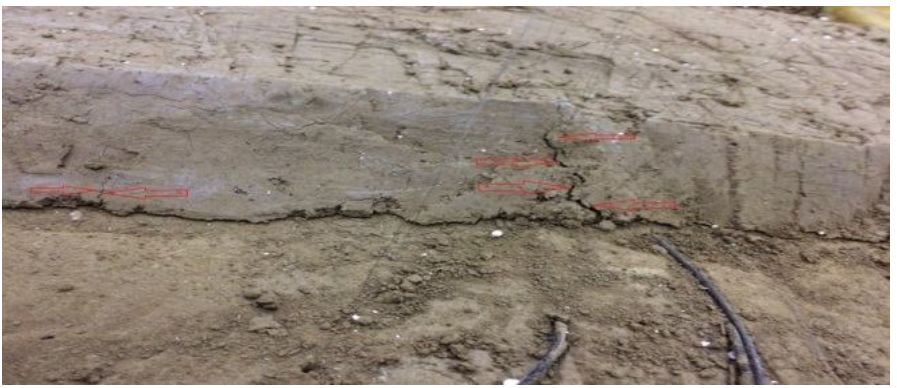

Figure 7: Cracks in the sloping part of the road sub-grade.

By the end of the experiment (the $15^{\text {th }}$ cycle of freezingthawing), longitudinal and transverse cracks were fixed on the model surface. The top view of the subgrade in the experimental model is shown in Figure 8.

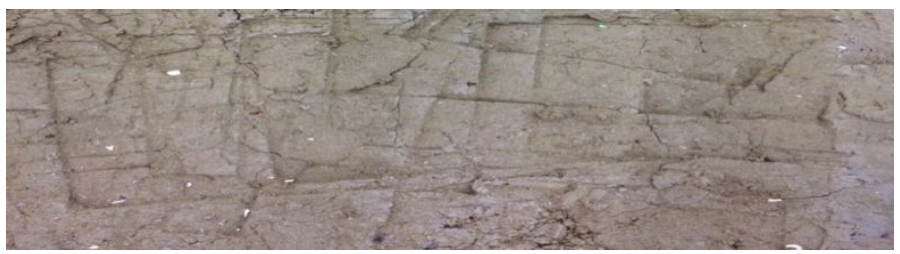

Figure 8: Top view of the experimental model.

\section{RESULTS OF THE RESEARCHES}

As a result of the experimental studies of the model of the roadbed of the road on permafrost soils, data on the development of the deformed state of the roadbed and the base of the road were obtained.

For a visual representation of the development of vertical displacements of the model of the subgrade and the base of the road in the program complex "Python", isolines of the distribution of vertical displacements during freezing-thawing were built (Figures 9,11,13,15), as well as thermograms of temperature changes in the body of the subgrade and the base of the road on permafrost soils, during thawing and freezing (Figures 10,12,14,16).
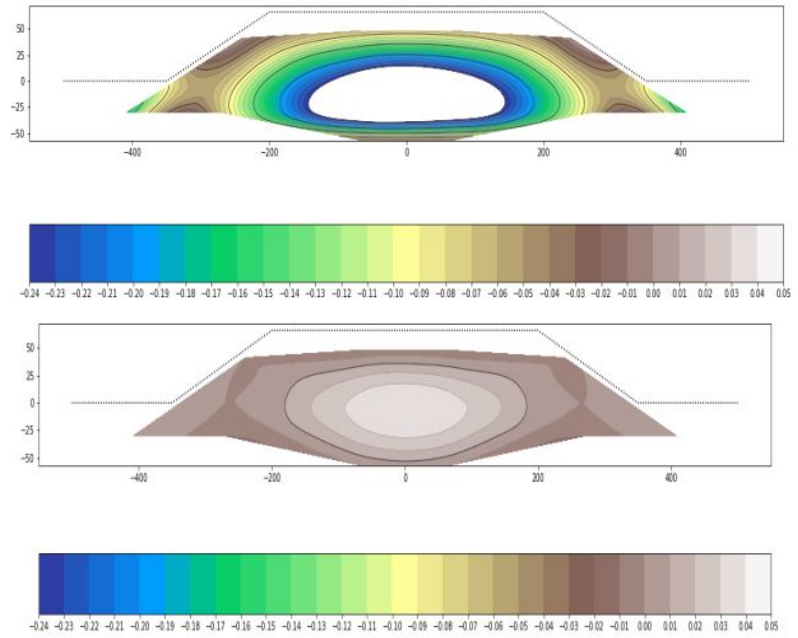

Figure 9:Isolines of vertical movements in the sub-grade model and the road base of permafrost soils while freezing, $\mathrm{mm}$.
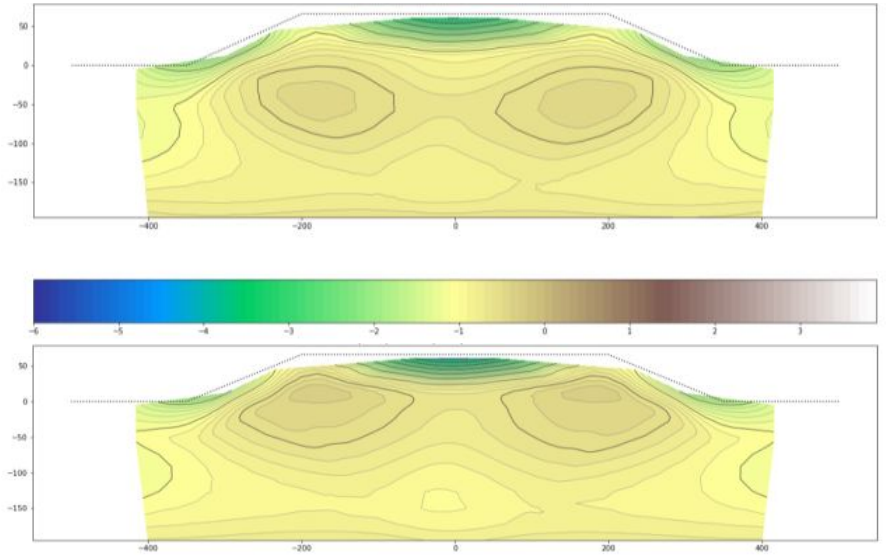

Figure 10: Thermograms of temperature changes in the body of the sub-grade and the base of the road on permafrost while freezing, $\mathrm{C}^{\circ}$.
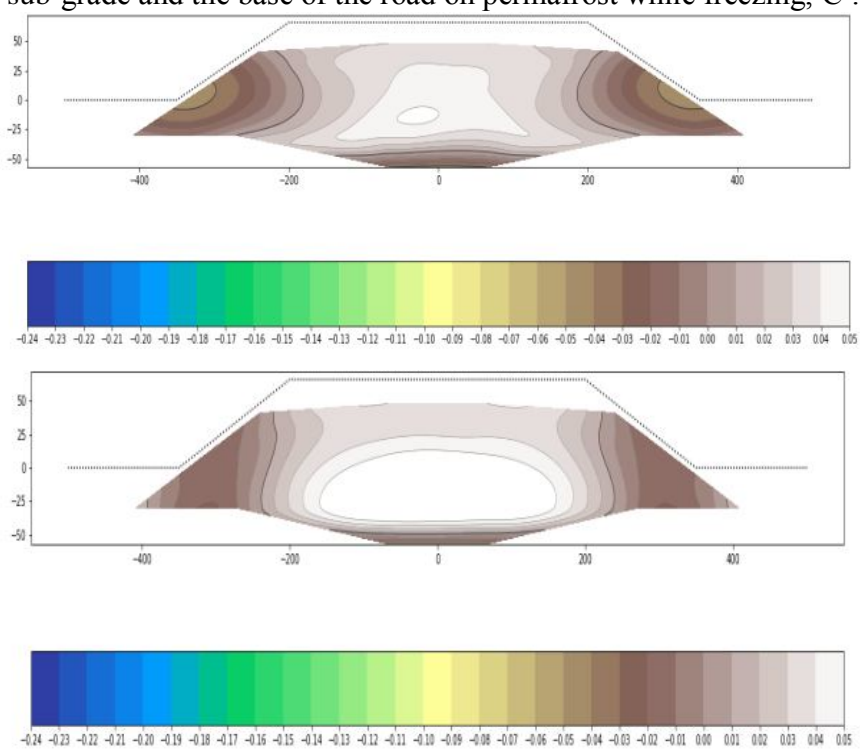

Figure 11:Isolines of vertical movements in the sub-grade model and the road base of permafrost soils while freezing, $\mathrm{mm}$.
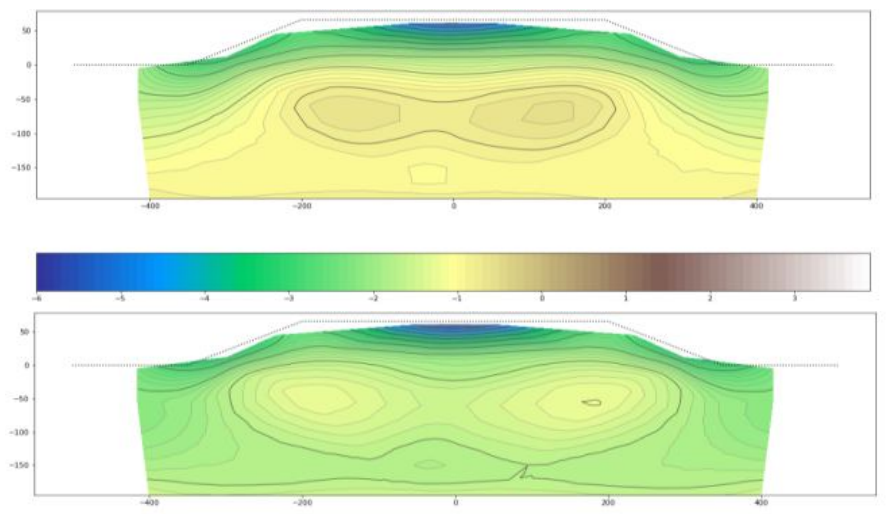

Figure 12: Thermograms of temperature changes in the body of the sub-grade and the base of the road on permafrost while freezing, $\mathrm{C}^{\circ}$. 
Aleksey KRAEV et al., International Journal of Emerging Trends in Engineering Research, 8(9), September 2020, 5083- 5087
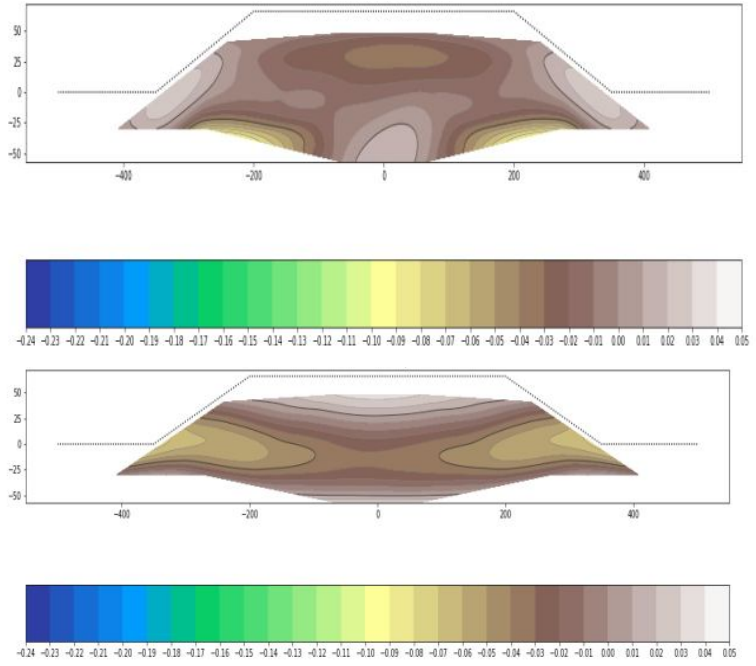

Figure 13: Isolines of vertical movements in the sub-grade model and the road base of permafrost soils while thawing, $\mathrm{mm}$.
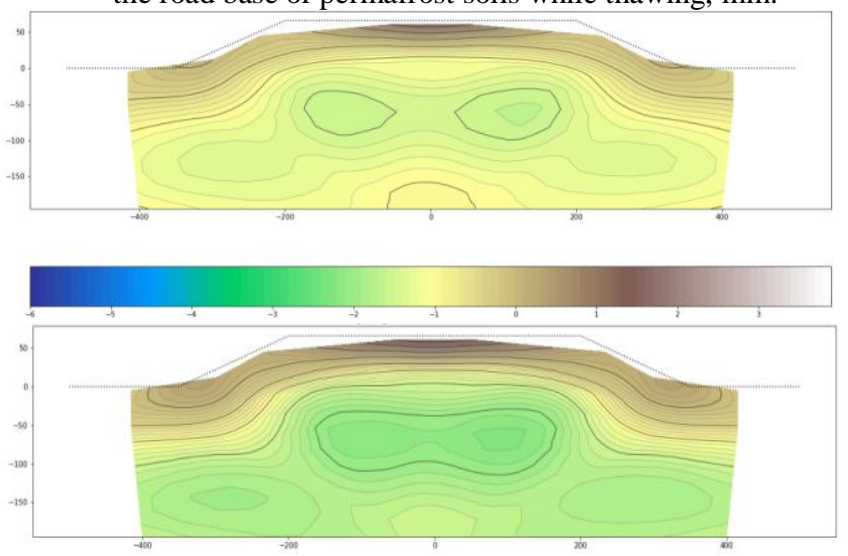

Figure 14: Thermograms of temperature changes in the body of the sub-grade and the base of the road on permafrost while thawing, $\mathrm{C}^{\circ}$.
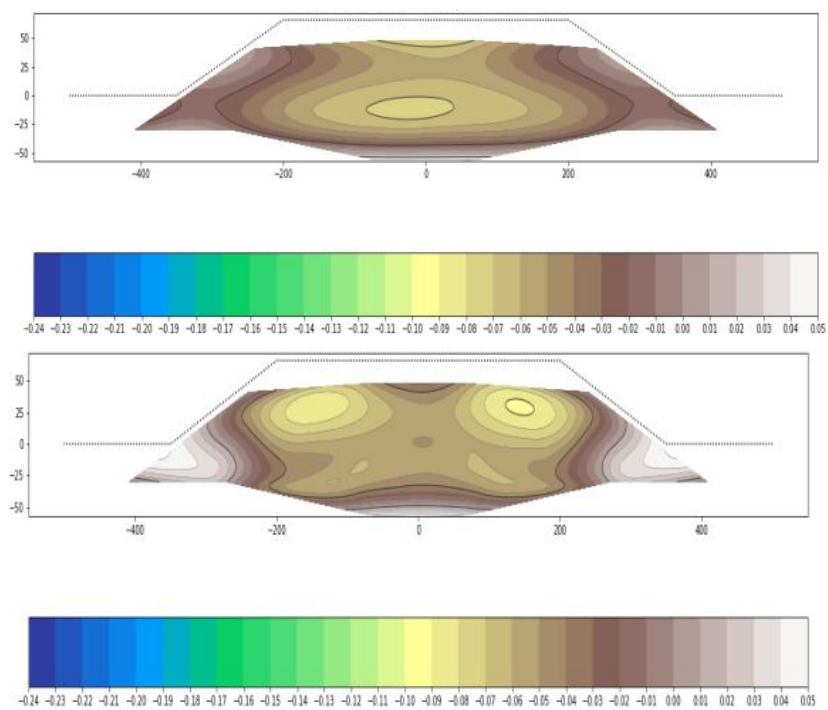

Figure 15: Isolines of vertical movements in the sub-grade model and the road base of permafrost soils while thawing, $\mathrm{mm}$.
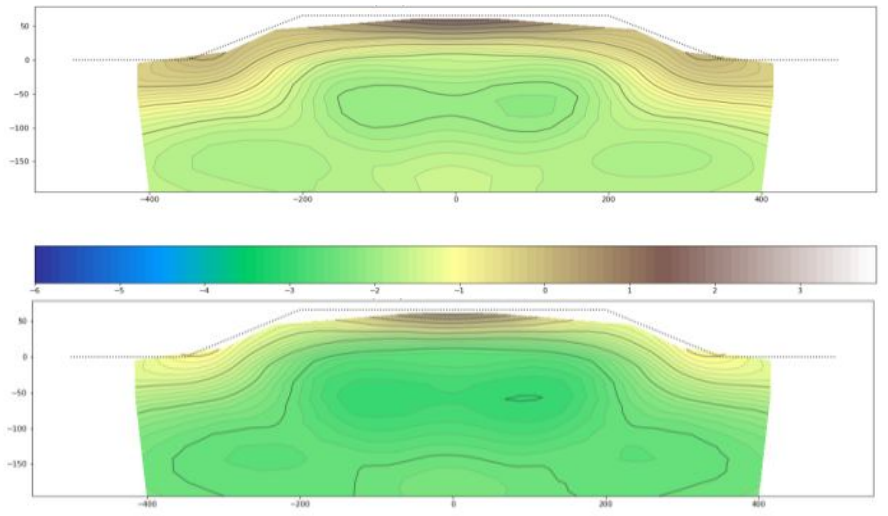

Figure 16: Thermograms of temperature changes in the body of the sub-grade and the base of the road on permafrost while thawing, $\mathrm{C}^{\circ}$.

Vertical displacements (Figures 9,11,13,15), recorded along the axis of the structure and in the slope of the roadbed, indicate a cyclical rise and fall of the upper permafrost horizon. With each subsequent freeze-thaw cycle, the formation of a frozen core in the body of the subgrade is traced, which is typical for highways in the permafrost zone and is in good agreement with the results of observations by other authors.

According to the results of experimental measurements of the temperature regime (Figures 10,12,14,16) of the model of the roadbed of a motor road on permafrost soils, it can be seen that the process of thawing-freezing of the structure of the roadbed occurs faster on the surface and in the slope of the structure, as evidenced by the data of the isolines displacement.

The results of measurements of displacements and soil temperature in the article are presented for 10 cycles, since from 10 to 15 the cycle of changing the value of temperature and deformation in the model is cyclically repeated, that is, the subgrade and the base of the road are conditionally stabilized.

\section{CONCLUSIONS}

According to the results of experimental studies of the deformed state of the sub-grade model on permafrost soils, the following conclusions can be made:

1. Conducting laboratory experiments simulating the work in difficult climatic and engineering-geological conditions is an economically feasible task, which allows investigating and implementing new technical solutions.

2. To simulate the most unfavorable operating conditions of the structure, it is necessary to implement an open road base system (to provide moisture inflow) in the experimental flume and simulate snow cover.

3. The high speed of freezing of the slope of the sub-grade and the roadside of the base is not consistent with the results of field observations and studies of other authors, which indicates the need for snow cover modeling during freezing.

4. The efficiency of new constructive and technical solutions to stabilize the sub-grade and the road base on permafrost soils is proposed to be evaluated through the results of numerical experiments with subsequent modeling of the structure in the laboratory using similarity criteria. 


\section{REFERENCES}

[1] Al.N.Kraev and T.V. Permitina."Methodology for laboratory research of a motor road on permafrost soils", Collection of materials of the XV scientific-practical conference of young scientists, graduate students, applicants and undergraduates of TyumGASU - In 2 volumes. - V. I. Tyumen: RIO TyumGASU,pp. 64-72, 2015

[2] Z.Sh.Shankhoev, Al.N. Kraev."Analysis and causes of the destruction of highways on permafrost soils", Collection of materials of the XV scientific-practical conference of young scientists, graduate students, applicants and undergraduates of TyumGASU - In 2 volumes. - V. I. - Tyumen: RIO TyumGASU, pp. 206-213. 2015.

[3] A.S.Makarov, A.N.Kraev, S.A. Tverdokhleb, Z.Sh. Shankhoev."Results of experimental research and numerical modeling of plane-parallel freezing of a soil sample in an experimental stand", Transport structures, No. 4, 2017.

DOI: 10.15862 / 09TS417.

[4] A.S.Makarov, Z.Sh.Shankhoev, I.V.Zemerov, D.S. Skvortsov."Analysis of the scale factor in modeling a road on permafrost", New technologies for the oil and gas region: materials of the international scientific and practical conference,V. 4. - Tyumen: TIU - pp. 256-259, 2017.

[5] Z.Sh.Shankhoev, A.S.Makarov, T.V.Permitina "Monitoring systems for highways on permafrost soils within the framework of the Smart Roads project", New technologies for the oil and gas region: materials of the international scientific and practical conference, V. 5. Tyumen: TIU, pp. 335-337, 2017.

[6] Scientific works of JSC TsNIIS issue No. 236 construction of railways and highways in permafrost regions. Moscow, 2011.

[7] V.V. Vorontsov, Al.N. Kraev, M.E. Igoshin."Stabilization of critical deformations of the road bed of a motor road in permafrost", Bulletin of the Siberian State Automobile and Road Academy. - Omsk: Federal State Budgetary Educational Institution of Higher Professional Education "Siberian State Automobile and Road Academy (SibADI)", pp. 67-72, 2014.

[8] M.E. Igoshin, Yu.V. Ogorodnova, Yu.S. Koroyan, T.V. Permitina. "Numerical modeling of the stress-strain state of the embankment body and the active layer at the base of the road structure using various schemes of reinforcement with geotextiles", Collection of materials of the All-Russian scientific-practical conference "Actual problems of construction, ecology and energy conservation in Western Siberia.", Tyumen: RIO FGBOU VPO, pp. 115-118, 2012.

[9] VSN 84-89 Research, design and construction of highways in permafrost areas, 1989.

[10] N.A. Tsytovich.Mechanics of frozen soils. Tutorial. Moscow.: Higher. shk., 448 p., 1973.

[11] V.D. Karlov. Seasonally freezing soils as foundations of structures: dis. Dr. tech. sciences. SPb., 1998.

[12] M. Karthik, V.B. Shashank and V.G. Ajey Kumar. "An experimental study of pavement quality concrete for rural roads in india using plastic and industrial wastes", International Journal of Emerging Trends in Engineering Research, 8(8), pp. 4287-4292, 2020.

doi:10.30534/ijeter/2020/39882020.

[13] M.H.Fahmi, A.Z.Saber and K.H. Younis. "Statistical analysis and prediction models for performance of remixed concrete in hot climate regions". International Journal of Emerging Trends in Engineering Research, 8(8), pp. 41784184, 2020. doi:10.30534/ijeter/2020/24882020 